\title{
A Study on Gold(III) Recovery Via Foam Separation with Nonionic Surfactant in Batch Mode
}

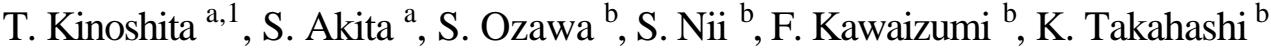 \\ ${ }^{a}$ Nagoya Municipal Industrial Research Institute, 3-4-41 Rokuban, Atsuta-ku, \\ Nagoya 456-0058, Japan \\ address ${ }^{1}$ Fax: +81-52-654-6788. e-mail: kinoshita.takehiko@nmiri.city.nagoya.jp \\ ${ }^{b}$ Department of Chemical Engineering, Nagoya University, Chikusa-ku, \\ Nagoya 464-8603, Japan
}

\begin{abstract}
Foam separation of $\mathrm{Au}(\mathrm{III})$ from its hydrochloric acid solutions was studied in a batch mode using a nonionic surfactant: polyoxyethylene nonyl phenyl ether having 20 ethylene oxide units (PONPE20). The surfactant showed a strong affinity to $\mathrm{Au}(\mathrm{III})$ in $\mathrm{HCl}$ media and played a double role of foam-producer and metal-collector. Effects of experimental parameters, such as the length of drainage section of the column, concentration of the surfactant and the metal, air flow rate and solution temperature, were discussed in terms of the recovery and the enrichment of $\mathrm{Au}(\mathrm{III})$. The recovery increased with an increase in the concentration of surfactant and in air flow rate, while the enrichment improved with decreasing air flow rate and increasing the length of drainage section. The behavior of $\mathrm{Au}$ (III) adsorption onto the foam was also analyzed in terms of the surface excess, and the Freundlich's adsorption isotherm was successfully applied to the system. Moreover, the selective separation of $\mathrm{Au}$ (III) from several heavy metals and the application of cloud point extraction to the present foamate solution were also carried out with the resultant enrichment ratio of 59.
\end{abstract}

Key Words: foam separation, nonionic surfactant, gold(III), surface excess, Freundlich's adsorption isotherm, cloud point extraction

\section{Introduction}

Conventional hydrometallurgical processes for recovering precious metals generally consist of multiple steps of dissolution (leaching), conditioning and precipitation. These are not only labor-intensive but also time-consuming, and much work has been conducted on the development of alternative methods including solvent extraction and ion exchange. In hydrochloric acid, gold exists exclusively as tetrachloro-anion ( $\mathrm{AuCl}_{4}^{-}$) [1]. Ion pair extractants such as amine salts are utilized to extract this anionic species [2,3], while solvating extractants including methyl isobutyl ketone [4] and dibutylcarbitol (diethyleneglycol dibutyl ether) [1] are adopted in the extraction of its parent acid, tetrachloroauric acid ( $\mathrm{HAuCh}_{4}$ ). Among other extractants examined are di(2-ethylhexyl) phosphoric acid, guanidine-based compound and alkyliminodimethylene phosphonic acid [3-5]. 
Polyoxyethylene nonyl phenyl ethers (PONPEs) are commonly and widely used nonionic surfactants with their relatively benign nature. The surfactants have a number of electron-donating oxygen atoms in their ethylene oxide (EO) chains, and form complexes with various metal ions [6,7] in the same manner as solvating extractants. In our previous studies, gold was found to be strongly complexed with the nonionic surfactants in hydrochloric acid media, and we have examined the separation of gold in such unit operations as solvent extraction [8], cloud point extraction [9] and micellar-enhanced ultrafiltration [10]. Cloud point extraction utilizes spontaneous coacervation of aqueous PONPE solutions at temperatures above the cloud point; the metal is concentrated into the small coacervate (surfactant-rich) phase from the bulk aqueous (surfactant-poor) phase. In micellar-enhanced ultrafiltration, gold is entrapped in the surfactant micelles and concentrated in the residual phase since the micelles can not pass through the ultrafiltration membrane having pores smaller than the micelles. In these methods, however, the complete recovery of gold is difficult to attain since a small amount of the surfactant remains in the bulk aqueous phase in the monomeric form below the critical micelle concentration.

Foam fractionation is another promising surfactant-based separation process which features minimum requirements for the energy input and the operational costs. The technique is particularly attractive for treating dilute solutions; a variety of applications have been reported from mineral ore [11-13], hazardous metal ions [11,12], proteins [14,15] to surfactants [16]. In the process, foam produced by bubbling travels upward in a column while draining the interstitial water between the foam and is collected in a reservoir; solutes to be removed or recovered are adsorbed onto the foam surface and concentrated in the collapsed foam liquid (foamate) phase. A foam producing agent, i.e. surface active reagent, is added to feed solution to stabilize the foam, while a collector is often introduced into the system to make target solutes surface active and collectable. Numerous researches were conducted on the combination of such additives and target solutes under various conditions [17-20].

In this study, foam separation of gold(III) from hydrochloric acid solutions was carried out in a batch mode using the nonionic surfactants. Effects of several experimental parameters were investigated on the recovery and enrichment of the metal. The surfactants are expected to work as both foam-producing and collector agent, thus, reducing a reagent inventory.

\section{Materials}

Nonionic surfactants, polyoxyethylene nonyl phenyl ethers (PONPEs), with average ethylene oxide units of 7.5, 10 and 20 were obtained from Tokyo Kasei Kogyo Co., Ltd. and used without further purification. The general formula is $\mathrm{HO}\left(\mathrm{CH}_{2} \mathrm{CH}_{2} \mathrm{O}\right)_{n} \mathrm{C}_{6} \mathrm{H}_{4} \mathrm{C}_{9} \mathrm{H}_{19}$, where $\mathrm{n}$ is the ethylene oxide number. Aqueous metal solutions were prepared by dissolving each metal chloride in dilute hydrochloric or nitric acid solutions. All the chemicals used were of reagent grades. 


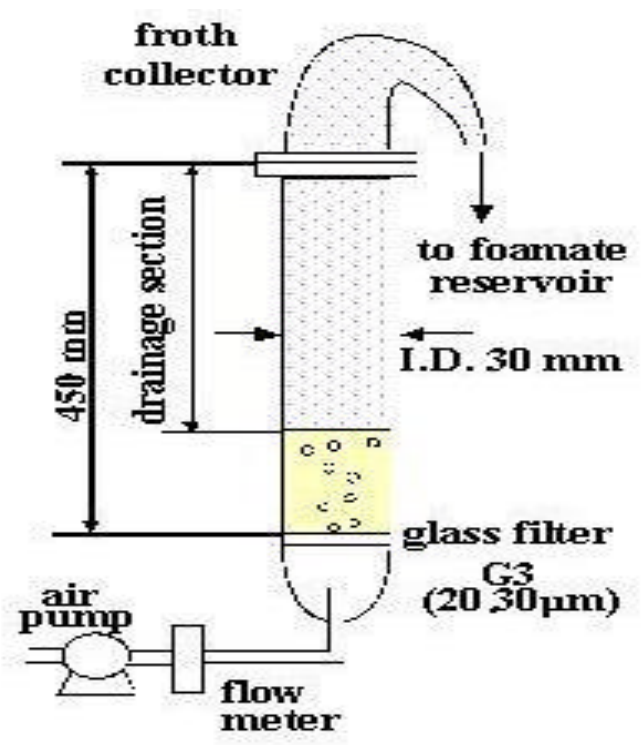

Figure 1. Schematic diagram of foam separation apparatus.

\section{Procedure for Foam Separation Experiments}

A schematic diagram of foam separation apparatus employed in this study is shown in Figure 1. The bubble column is composed of a cylindrical glass tube ( $450 \mathrm{~mm}$ in height and 30 $\mathrm{mm}$ in inner diameter) with a sintered glass filter (G3) mounted at a lower part of the column as a gas distributor. Initial concentrations of metal, surfactant and acid were set at $20 \mathrm{ppm}, 0.05$ wt\% and $2.0 \mathrm{M}$, respectively, except for the experiments on their effects. The feed solution was charged into the column to the height of $10 \mathrm{~cm}$ from the glass filter (ca. $78 \mathrm{ml}$ ), and air bubbles were introduced through the distributor by an air compressor at $40 \mathrm{ml} / \mathrm{min}$, unless otherwise stated. The foam was collected through a froth collector equipped at the top of the column connected to a foamate reservoir. Air flow was stopped when no more foam appeared from the bulk solution. Experiments were carried out at $298 \mathrm{~K}$.

Metal concentrations in the foam liquid (foamate) and residual (retentate) phases were determined by inductively coupled plasma spectroscopy (ICP) after appropriate dilution. A residual amount of the surfactant in the retentate phase was determined by UV spectrophotometry at $276.0 \mathrm{~nm}$. An average diameter of the foam was estimated by photographing the column content and measuring the radius of each foam.

Experiments on cloud point extraction were also carried out using both specially prepared and actual foamate solutions after the foam separation. A prescribed amount of PONPE7.5 was added to the feed solution $(20 \mathrm{ml})$ containing Au(III), PONPE20 and $\mathrm{HCl}$. After mixing, the solution was kept overnight in a incubator to attain the phase separation. Then, the volume of the coacervate phase was measured; the metal concentration in the aqueous (surfactant-poor) phase was measured by ICP and that in the coacervate phase was determined from a mass balance. 


\section{Results and Discussion}

\section{Foam separation of $A u(I I I)$ from hydrochloric acid media}

In this study, the efficiency of foam separation was evaluated in terms of the recovery percent $(\mathrm{R})$ and enrichment ratio $(\mathrm{E})$ defined by the following equations:

$$
\begin{aligned}
& \mathrm{R}_{\mathrm{fm}}=100\left(\mathrm{~V}_{\mathrm{fm}} / \mathrm{V}_{\mathrm{ini}}\right) \\
& \mathrm{R}_{\mathrm{M}}=100\left(\mathrm{~V}_{\mathrm{fm}}[\mathrm{M}]_{\mathrm{fm}} / \mathrm{V}_{\text {ini }}[\mathrm{M}]_{\text {ini }}\right) \\
& \mathrm{E}=[\mathrm{M}]_{\mathrm{fm}} /[\mathrm{M}]_{\text {ini }}=\mathrm{R}_{\mathrm{M}} / \mathrm{R}_{\mathrm{fm}}
\end{aligned}
$$

where $\mathrm{M}$ represents metal, and the subscripts, fm and ini, refer to the foamate phase and the feed solution, respectively.

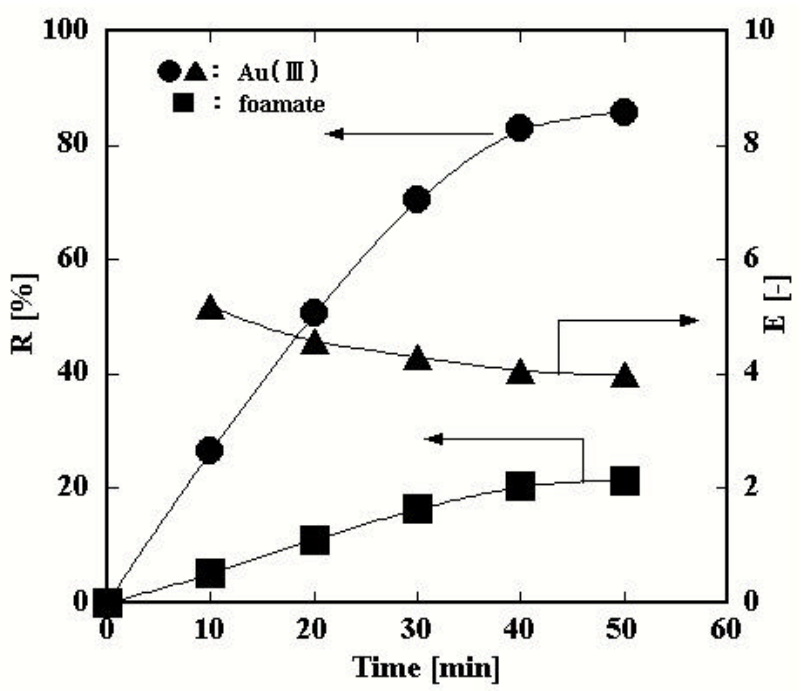

Figure 2. Time course of foam separation of Au(III) using $0.05 \mathrm{wt} \%$ PONPE 20 in $2.0 \mathrm{M} \mathrm{HCl}$.

Typical results for the time course of foam separation of $\mathrm{Au}(\mathrm{III})$ with $0.05 \mathrm{wt} \%$ PONPE20 from 2.0 M hydrochloric acid solution are shown in Figure 2. Initial concentration of the metal was set to be $20 \mathrm{ppm}$. On starting bubbling (40 ml/min), stable foam was produced and the generation of foam continued for ca. $50 \mathrm{~min}$ until the surfactant became insufficient in the bulk solution. The foam collected in the reservoir defoamed spontaneously. As the bubbling proceeds, $\mathrm{Au}$ (III) also accumulates in the foamate phase with the final recovery as high as $86 \%$, implying the strong interaction between the metal and the surfactant. Since Au(III) exists in the form of $\mathrm{AuCh}_{4}^{-}$in hydrochloric acid, the adsorption should take place through the coordination of

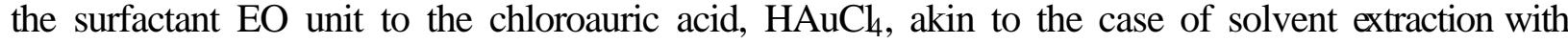
solvating extractants. Thus, the surfactant successfully plays a double role of foam-producer and collector, and the separation of $\mathrm{Au}(\mathrm{III})$ can be attained with this simple technique. On the other hand, a slight decrease in the enrichment ratio of $\mathrm{Au}$ (III) from 5.2 to 4.0 is observed with time. This can be ascribed to an increase in the volume of the foamate phase, caused by the interstitial water existing between foams. The final recovery of foamate is $22 \%$. In nitric acid media under the same experimental conditions, though the data are not shown here, the foam was less stable 
than in hydrochloric acid; the final values were $36 \%$ in the recovery and 3.1 in the enrichment ratio of $\mathrm{Au}(\mathrm{III})$.

TABLE I. Effect of length of drainage section and height of feed solution on efficiency of foam separation.

\begin{tabular}{cccccc}
\hline Height of feed solution $(\mathbf{c m})$ & 10 & 20 & 30 & 10 & 10 \\
Length of drainage secction $(\mathbf{c m})$ & 35 & 35 & 35 & 65 & 85 \\
\hline $\mathbf{R}_{M}(\%)$ & 86 & 83 & 84 & 79 & 72 \\
$\mathbf{R}_{\text {fm }}(\%)$ & 22 & 21 & 21 & 10 & 8.6 \\
$\mathbf{E}(-)$ & 4.0 & 4.0 & 3.9 & 7.9 & 8.5 \\
Run time (min) & 50 & 109 & 157 & 66 & 65 \\
\hline
\end{tabular}

In foam separation, the interstitial water between foams is drained out in the drainage section in the column during upward travel of the foam from the bulk liquid surface to the top of the column. The degree of water drainage strongly affects the enrichment of target solutes and is a crucial factor in the process. In Table I are summarized the effects of both height of feed solution and length of the drainage section, the latter being altered by inserting extending tubes on the top of the column. When the length of drainage section is kept constant, an increase in the height of feed solution has little effect on both recovery of $\mathrm{Au}(\mathrm{III})$ and foamate, though the run time defined as the duration for the surfactant in the bulk solution to deplete increases from 50 $\min ($ at $10 \mathrm{~cm})$ to $157 \min (30 \mathrm{~cm})$ due to an increased volume of the feed solution. On the contrary, much improvement in the enrichment is observed by extending the drainage section. A slight decrease in the metal recovery is canceled out by smaller volume of the foamate phase, and the enrichment ratio reaches as high as 8.5 at the length of $85 \mathrm{~cm}$ compared with 4.0 at 35 $\mathrm{cm}$. In the following experiments, the heights of feed solution and the length of drainage section were set at $10 \mathrm{~cm}$ and $35 \mathrm{~cm}$, respectively.

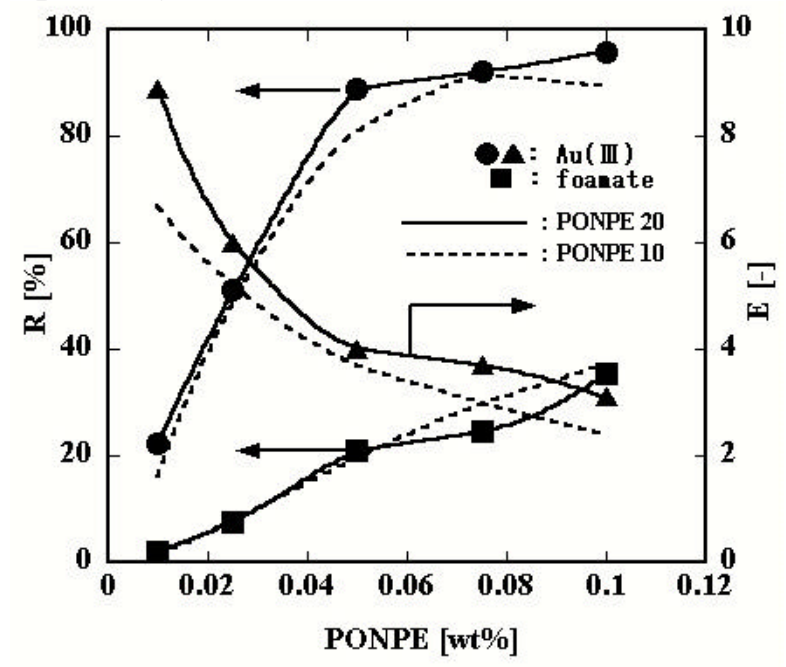

Figure 3. Effect of initial PONPE concentration on recovery percent and enrichment ratio. 
Results for the effect of the initial concentration of PONPE20 on the recovery and enrichment of $\mathrm{Au}(\mathrm{III})$ are shown in Figure 3. By increasing PONPE20 concentration to 0.05 $\mathrm{wt} \%$, the recovery of $\mathrm{Au}(\mathrm{III})$ increases dramatically to $86 \%$ and reaches plateau at higher surfactant concentrations. However, increasing volume of the foamate phase leads to a decline in the enrichment ratio of $\mathrm{Au}$ (III) from 8.9 to 4.0. Taking into account the contradicting influences on the recovery and the enrichment, the optimum concentration for PONPE20 is determined to be $0.05 \mathrm{wt} \%$ for $\mathrm{Au}(\mathrm{III})$ separation in the present system. At this concentration, the molar ratio of the surfactant to the metal corresponds to 4.5. When the surfactant concentration exceeded 0.10 wt $\%$, stable operation could not be attained due to excessive formation of foam from the onset of bubbling. Results for the system using PONPE10 are also given in Figure 3 by the dotted lines, indicating slightly lower efficiency than that of PONPE20. The difference in performance between the two surfactants is ascribed to the difference in their foamability rather than the extractability of $\mathrm{Au}(\mathrm{III})$ since the total amounts of ethylene oxide units existing in the two systems are similar.

TABLE II. Effect of air flow rate on efficiency of foam separation.

\begin{tabular}{ccccc}
\hline Air flow rate (ml/min) & 30 & 40 & 50 & 60 \\
\hline $\mathbf{R}_{M}(\%)$ & 77 & 86 & 84 & 92 \\
$\mathbf{R}_{\text {fm }}(\%)$ & 11 & 22 & 24 & 31 \\
E (-) & 7.3 & 4.0 & 3.5 & 3.0 \\
Run time (min) & 75 & 50 & 44 & 38 \\
\hline
\end{tabular}

The effect of air flow rate on the system is tabulated in Table II. By rising the flow rate, the run time is reduced from $75 \mathrm{~min}$ at $30 \mathrm{ml} / \mathrm{min}$ to $38 \mathrm{~min}$ at $60 \mathrm{ml} / \mathrm{min}$. While the metal recovery is relatively high, a rise in the flow rate leads to a significant decrease in the enrichment from 7.3 to 3.0. The decline can be attributed to an increased amount of the interstitial water transferred to the reservoir as reflected in an increase in the recovery of foamate.

TABLE III. Effect of initial Au(III) concentration on efficiency of foam separation.

\begin{tabular}{lllllll}
\hline Initial Au(III) concentration $(\mathbf{p p m})$ & 10 & 20 & 40 & $\mathbf{8 0}$ & $\mathbf{1 2 0}$ & $\mathbf{2 0 0}$ \\
\hline $\mathbf{R}_{\mathrm{M}}(\%)$ & 91 & $\mathbf{8 6}$ & $\mathbf{6 6}$ & $\mathbf{5 1}$ & $\mathbf{4 4}$ & $\mathbf{3 6}$ \\
$\mathbf{R}_{\mathrm{fm}}(\%)$ & 18 & 22 & 18 & 19 & 19 & 19 \\
$\mathbf{E}(-)$ & 5.0 & 4.0 & 3.6 & 2.7 & 2.3 & 1.9 \\
Molar ratio & 9.0 & 4.5 & 2.2 & 1.1 & 0.75 & 0.45 \\
\hline
\end{tabular}

Results for the effect of initial Au(III) concentration is given in Table III, along with the molar ratio of PONPE20 to the metal in each system. At the metal concentration of $10 \mathrm{ppm}$, at which the molar ratio corresponds to 9.0 , the recovery reaches over $90 \%$ with the enrichment ratio of 5.0. Increase in the initial $\mathrm{Au}$ (III) concentration leads to a considerable decrease in the metal recovery as the result of depletion of the surfactant; the recovery is reduced to as low as 36 $\%$ at $200 \mathrm{ppm}$. It is to be noted that the residual metal could be recovered by adding the surfactant into the retentate phase and conducting the bubbling again. Since only a limited 
amount of the surfactant can be introduced into the system for the reason described above, the present system is more appropriate in handling solutions containing a small or trace amounts of metals.

TABLE IV. Effect of solution temperature on efficiency of foam separation.

\begin{tabular}{ccccc}
\hline Temp. $(\mathbf{K})$ & 298 & 312 & 320 & 330 \\
\hline $\mathbf{R}_{\mathrm{M}}(\%)$ & $\mathbf{8 6}$ & 72 & $\mathbf{5 8}$ & 48 \\
$\mathbf{R}_{\mathrm{fm}}(\%)$ & 22 & 21 & 16 & $\mathbf{8 . 4}$ \\
$\mathbf{E}(-)$ & 4.0 & 3.4 & 3.6 & 5.7 \\
Residual surfactant conc. $($ wt $\%)$ & $\mathbf{0 . 0 0 6}$ & $\mathbf{0 . 0 1 2}$ & $\mathbf{0 . 0 1 6}$ & $\mathbf{0 . 0 1 9}$ \\
\hline
\end{tabular}

The nonionic surfactants are known to lose their surface activity at high temperatures. From this point, the effect of solution temperature on the foam separation of $\mathrm{Au}(\mathrm{III})$ using PONPE20 has been investigated; the results are listed in Table IV. As the temperature rises, the percent recovery of $\mathrm{Au}$ (III) decreases considerably; its value falls below $50 \%$ at $330 \mathrm{~K}$. Increased temperature prevents the stable formation of foam and the subsequent adsorption of the metal on the foam surface, as ascertained by a decrease in the foamate volume recovered. These results indicate that careful control of temperature must be introduced in the foam separation process with nonionic surfactants. For the treatment a higher temperatures, the use of more hydrophilic nonionic surfactant having longer ethylene oxide units might be promising. Each residual concentration of PONPE20 in the retentate phase is also tabulated in Table IV. At $298 \mathrm{~K}$, less than one-tenth, $0.006 \mathrm{wt} \%$, of the initial surfactant concentration remains in the bulk solution. Although the value is well below the critical micelle concentration (CMC) of the surfactant $(0.015 \mathrm{wt} \%$ at $298 \mathrm{~K})$ [21], the retentate solution is recommended to be recycled or treated in downstream process, such as activated carbon treatment. The residual concentration increases by a rise in the solution temperature, and reaches $0.019 \mathrm{wt} \%$ at $330 \mathrm{~K}$.

\section{Separation of $\mathrm{Au}(\mathrm{III})$ and cloud point extraction}

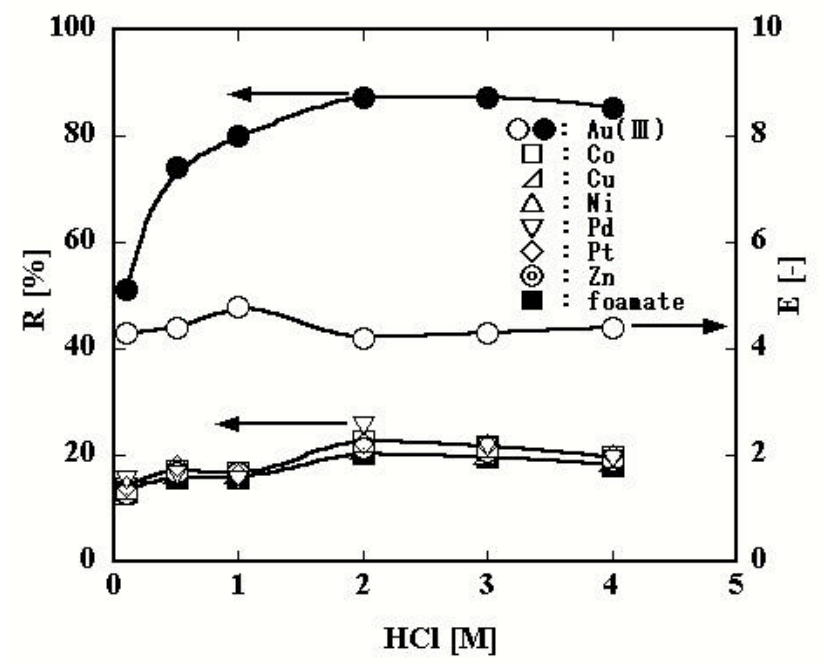

Figure 4. Effect of $\mathrm{HCl}$ concentration on foam separation using $0.05 \mathrm{wt} \%$ PONPE 20 from multi metal solution. 
Experiments on the selective recovery of $\mathrm{Au}(\mathrm{III})$ from multi-metals solution of $\mathrm{Co}(\mathrm{II})$, $\mathrm{Cu}(\mathrm{II}), \mathrm{Ni}(\mathrm{II}), \mathrm{Pd}(\mathrm{II}), \mathrm{Pt}(\mathrm{IV})$ and $\mathrm{Zn}$ (II) have been carried out via the foam separation using PONPE20. Figure 4 shows the effect of hydrochloric acid concentration on the recovery percent of each metal and the enrichment ratio of $\mathrm{Au}$ (III). Initial concentration of each metal was 20 ppm, and the acid concentration was varied from 0.1 to $4.0 \mathrm{M}$. The recovery percent of $\mathrm{Au}$ (III) increases with increasing $\mathrm{HCl}$ concentration, and exceeds $85 \%$ at acid concentrations more than 2.0 M. The similar trend was observed in the solvent extraction of Au(III) using PONPEs [7], implying the same complexing mechanism in hydrochloric acid media. On the other hand, the transfer of the other metals to the foamate phase is much suppressed to below $20 \%$ in the whole acid range studied; thus, satisfactory separation of $\mathrm{Au}(\mathrm{III})$ is attainable. The percent recovery of foamate, though the data are not shown here, was found to be quite similar to that of the other metals. This coincidence implies that the metals are not adsorbed onto the surface of foam through the specific interaction with the surfactant, but move within the interstitial water into the foamate phase. The following conclusion can also be deduced from the above observation: about three quarters of $\mathrm{Au}(\mathrm{III})$ are entrained on the foam interface while the rest is conveyed with the interstitial water based on the difference in the recovery percent of $\mathrm{Au}(\mathrm{III})$ and the other metals.

The degree of the adsorption of $\mathrm{Au}$ (III) onto the surface of foam was analyzed in terms of surface excess, $\Gamma$, determined by a mass balance on the foamate phase:

$$
\mathrm{L}[\mathrm{M}]_{\mathrm{fm}}=\mathrm{S} \Gamma+\mathrm{L}[\mathrm{M}]_{\text {ret }}
$$

where the subscript, ret, refers to the retentate phase, L and S denote the volumetric flow rate of foamate and the surface generation rate of foam, respectively. The first term in the right side of Equation (4) corresponds to the metal entrainment on the foam surface, and the second term corresponds to the metal conveyed in the interstitial water. An air flow rate $(\mathrm{F})$ and an average diameter of foam (d) were used to calculate the surface generation rate $6 \mathrm{~F} / \mathrm{d}$, provided that the foam produced is a perfect sphere and uniform. Under the standard experimental condition, the foam diameter was determined to be $0.7 \mathrm{~mm}$, and no significant change in the size was observed during runs.

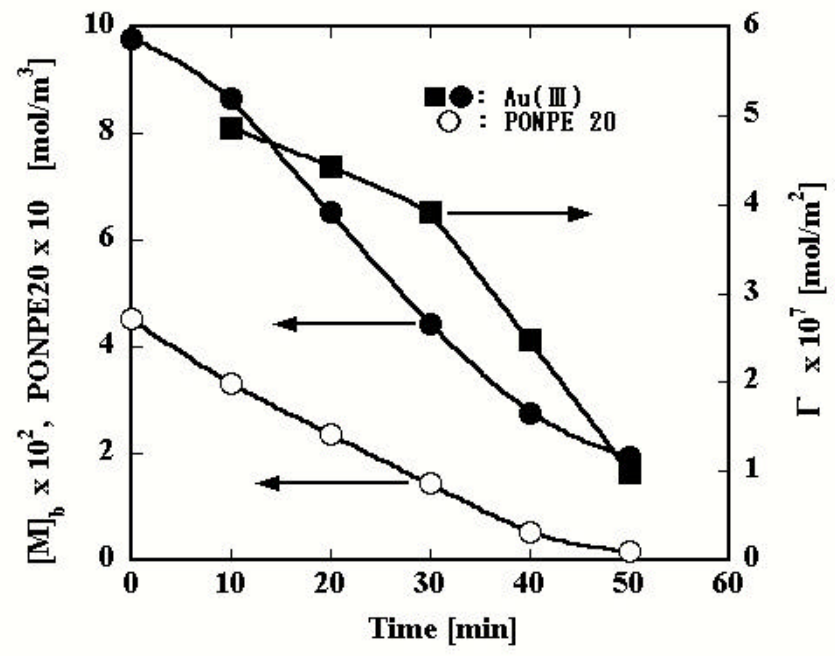

Figure 5. Time course of surface excess and retentate concentrations of $\mathrm{Au}(\mathrm{III})$ and PONPE. 
Figure 5 shows time course of the surface excess along with the retentate concentration of $\mathrm{Au}(\mathrm{III})$ and PONPE20. As the run proceeded, the concentrations of metal and surfactant decreased gradually to the end point, where no more foam was produced. The surface excess also decreased from 4.9 to $1.0 \times 10^{-7}$ and there appears an inflection point at around $30 \mathrm{~min}$. The fact that the residual concentration of surfactant at this point, $0.143 \mathrm{~mol} / \mathrm{m}^{3}$, was very close to its CMC $\left(0.140 \mathrm{~mol} / \mathrm{m}^{3}\right.$ or $\left.0.015 \mathrm{wt} \%\right)$ indicated the strong interaction between the metal-surfactant complex in the bulk aqueous solution and on the foam surface.

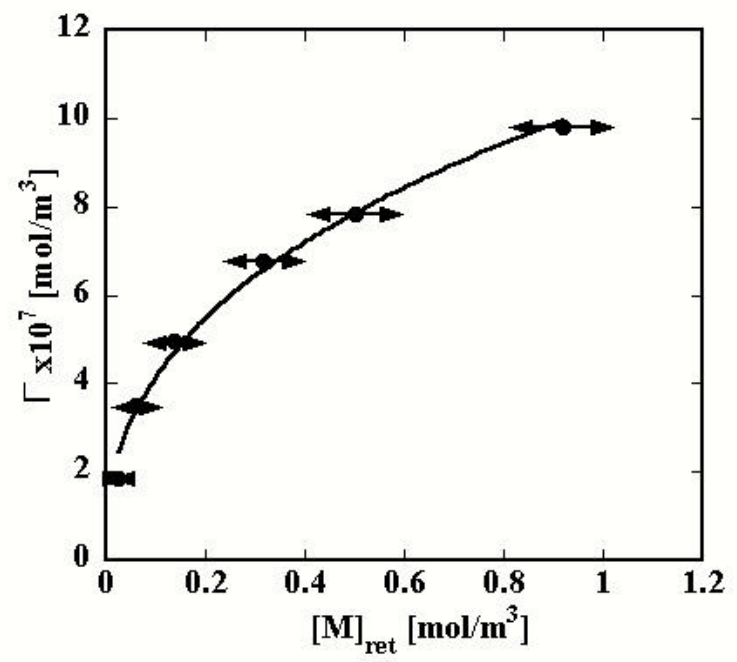

Figure 6. Relation between surface excess and retentate concentration of Au(III).

In Figure 6 the data in Table III are replotted using the as the surface excess against the concentration of $\mathrm{Au}(\mathrm{III})$ in the retentate, i.e. adsorption isotherm. Since the metal concentration in the retentate varies with time, an arithmetical mean between the initial and residual (final) values is adopted as $[\mathrm{M}]_{\text {ret }}$. As expected, the surface excess increased with increasing metal concentration, and can be well expressed by the following Freundlich's adsorption isotherm:

$$
\Gamma \times 10^{7}=10.3[\mathrm{M}]_{\mathrm{ret}} 0.39
$$

The solid line in Figure 6 is a calculated one using Equation. (5). The ranges which the arrows show are the transition of the concentration of $\mathrm{Au}(\mathrm{III})$ during runs.

With an intention to gain more concentrated metal solution, cloud point extraction had been applied to the foamate obtained in the foam separation. Coacervation, i.e. phase separation, of aqueous solutions of nonionic surfactant occured at temperatures above the system-intrinsic cloud point (CP) due to the dehydration of ethylene oxide units in the surfactant. Cloud point depended on several factors including the length of ethylene oxide units and the concentration of the surfactant; the longer are the ethylene oxide units, the higher are hydrophilicity of the surfactant and the cloud point of its aqueous solution. Since the cloud point of PONPE20 solution was well above the boiling point of water, more hydrophobic surfactant, PONPE7.5 was added to the solution to lower the cloud point. 
TABLE V. Effect of PONPE 7.5 added and settling temperature of cloud point extraction.

\begin{tabular}{ccccc}
\hline PONPE 7.5 added $(\mathrm{g})$ & Temp. $(\mathrm{K})$ & $\mathbf{V}_{\text {sur }}(\mathrm{ml})$ & $\mathbf{R}_{\mathbf{M}}(\%)$ & $\mathbf{E}(-)$ \\
\hline $\mathbf{0 . 4 0}$ & 303 & 4.0 & 96 & 4.8 \\
0.40 & 313 & 3.0 & 98 & 6.5 \\
0.40 & 323 & 2.3 & 92 & 8.0 \\
0.40 & 333 & 2.1 & 86 & 8.1 \\
0.31 & 333 & 1.7 & 86 & 10 \\
0.20 & 333 & 1.2 & 82 & 14 \\
0.12 & 333 & 0.99 & 75 & 15 \\
0.07 & 333 & 0.90 & 47 & 11 \\
\hline
\end{tabular}

Results of gold extraction using the cloud point extractive approach are shown in Table $\mathrm{V}$, which tabulates the percent extraction into the coacervate phase, $\mathrm{R}_{\mathrm{M}}$ and the enrichment ratio, $\mathrm{E}$, of $\mathrm{Au}(\mathrm{III})$. The concentration of $\mathrm{Au}(\mathrm{III}), \mathrm{PONPE} 20$ and $\mathrm{HCl}$ in the feed solution $(20 \mathrm{ml})$ was adjusted to be $80 \mathrm{ppm}, 0.2 \mathrm{wt} \%$ and $2.0 \mathrm{M}$, respectively, according to the standard composition obtained after the foam separation as described in the previous section. With increasing amount of PONPE7.5, cloud point decreased and the phase separation was attained at lower temperatures. To attain the phase separation, over $0.40 \mathrm{~g}$ of the surfactant is needed at $303 \mathrm{~K}$, while $0.07 \mathrm{~g}$ is sufficient at $333 \mathrm{~K}$. After the phase separation, adding $0.40 \mathrm{~g}$ PONPE7.5 and followed by heating, the $\mathrm{Au}(\mathrm{III})$ was successfully extracted into the small coacervate phase, giving the percent extraction of around $90 \%$. The volume of the coacervate phase, which contains both PONPE20 and PONPE7.5, can be reduced by raising the temperature. The enrichment ratio of $\mathrm{Au}(\mathrm{III})$ as high as 8.1 is attained at $333 \mathrm{~K}$ with the volume of $2.1 \mathrm{ml}$. As also can be seen in Table V, the lesser the amount of PONPE7.5 that is added, the smaller will be the volume of the coacervate phased formed at $333 \mathrm{~K}$. Though a slight decline in the percent extraction of $\mathrm{Au}(\mathrm{III})$ was observed with decreasing PONPE7.5, the enrichment ratio significantly increased and the metal concentration in the coacervate phase reached over 15 -fold of that in the initial solution.

Taking the above results into consideration, the cloud point extraction was applied to the foamate solution $(82 \mathrm{ppm})$ after the foam separation. With $0.09 \mathrm{~g}$ of PONPE7.5 added at $333 \mathrm{~K}$, $\mathrm{Au}(\mathrm{III})$ was extracted into the coacervate phase with the enrichment ratio 14 and the percent extraction $77 \%$. The concentration in the coacervate phase was $1184 \mathrm{ppm}$. The total enrichment of $\mathrm{Au}$ (III) from the feed solution (20ppm) was as high as 59 through the foam separation and subsequent cloud point extraction. Experiments on the foam separation of $\mathrm{Au}$ (III) using the nonionic surfactants in a continuous mode are underway in our laboratory.

\section{Conclusions}

Gold recovery from hydrochloric acid solution has been investigated via foam separation in a batch mode using the non-ionic surfactant, polyoxyethylene nonyl phenyl ether with 20 ethylene oxide units (PONPE20). On starting the bubbling, stable foams were formed and rose up through the column to make the small foamate phase, in which $\mathrm{Au}(\mathrm{III})$ was 
successfully concentrated with the surfactant. The recovery percent of $\mathrm{Au}$ (III) increased with an increase in the surfactant concentration, and decreased with an increase in the metal concentration or the solution temperature. The enrichment of $\mathrm{Au}(\mathrm{III})$ was improved by extending the drainage section of column, but deteriorated by increasing the concentrations of the surfactant and metal or rising the temperature.

The recovery of $\mathrm{Au}(\mathrm{III})$ was found to be based on two distinct paths: one is transfer on the foam surface and the other is in the interstitial water. The adsorption of $\mathrm{Au}$ (III) on the foam surface was well expressed by the Freundlich's adsorption isotherm in terms of the surface excess. Some heavy metals were not adsorbed onto the foam stabilized by PONPE20, and the selective foam separation of $\mathrm{Au}$ (III) could be attained from multi-metals solution. Moreover, cloud point extraction was successfully applied to the foamate solution by adding more hydrophobic nonionic surfactant, PONPE7.5, and raising the solution temperature, resulting in further enrichment of $\mathrm{Au}(\mathrm{III})$.

\section{Nomenclatures}

$\begin{array}{ll}\text { d } & \text { diameter of foam }[\mathrm{m}] \\ \text { E } & \text { enrichment ratio }[-] \\ \text { F } & \text { air flow rate }[\mathrm{ml} / \mathrm{min}] \\ \text { L } & \text { volumetric flow rate of foamate }\left[\mathrm{m}^{3} / \mathrm{min}\right] \\ \text { R } & \text { percent recovery or extraction }[\%] \\ \text { S } & \text { surface generation rate of foam }\left[\mathrm{m}^{2} / \mathrm{min}\right] \\ \text { V } & \text { volume }\left[\mathrm{m}^{3}\right] \\ \Gamma & \text { surface excess }\left[\mathrm{mol} / \mathrm{m}^{2}\right] \\ {[]} & \text { concentration }[\mathrm{ppm}] \text { or }\left[\mathrm{mol} / \mathrm{m}^{3}\right]\end{array}$

\section{Subscripts}

$\begin{array}{ll}\text { fm } & \text { foamate phase } \\ \text { ini } & \text { initial } \\ \text { ret } & \text { retentate phase } \\ \text { sur } & \text { coacervate phase } \\ \text { M, m } & \text { metal, i.e. Gold }\end{array}$

\section{References}

1. Cox, M., 1992, Solvent Extraction in Hydrometallurgy, In: Principles and Practices of Solvent Extraction, Chapter 10, pp. 381-393, (Rydberg, J., et al, Eds.), N.Y., Dekker.

2. Riveros, P.A., 1990, "Studies on the Solvent Extraction of Gold from Cyanide Media", Hydrometallurgy, Vol. 24, pp. 135-156.

3. Mooiman, M.B. and Miller, J.D., 1986, "The Chemistry of Gold Solvent Extraction from Cyanide Solution using Modified Amines", Hydrometallurgy, Vol. 16, pp. 245-261.

4. Mooiman, M.B. and Miller, J.D., 1991, "The Chemistry of Gold Solvent Extraction from Alkaline Cyanide Solution by Solvating Extractants", Hydrometallurgy, Vol. 27, pp. 29-46.

5. Kim,S.G.., Lee, H.Y., Oh, J.K., and Lee, E.C., 1995, "Stoichiometric Relation for the Extraction of Gold-Thiourea Complex with D2EHPA", Hydrometallurgy, Vol. 38, pp. 7-13.

6. Shen, Y.H., 1997, "Cloud Point Foaming Technique for Separation of Nonionic Surfactant 
from Solution”, Sep. Sci. Technol., Vol. 32 (13), pp. 2229-2235.

7. Akita, S. and Takeuchi, H., 1996, "Cloud Point Extraction of Gold(III) from Hydrochloric Acid Solution, in Value Adding through Solvent Extraction”, ISEC '96, Vol.1, pp. 529-534.

8. Akita, S., Yang, L. and Takeuchi, H., 1996, "Solvent Extraction of Gold(III) from Hydrochloric Acid Media by Nonionic Surfactant", Hydrometallurgy, Vol. 43, pp. 37-46.

9. Akita, S., Rovira, M., Sastre, A. M. and Takeuchi, H., 1998, Cloud Point Extraction of Gold(III) with Nonionic Surfactant - Fundamental Studies and Application to Gold Recovery from Printed Substrates", Sep. Sci. Technol., Vol. 33 (14), pp. 2159-2177.

10. Akita, S., Yang, L. and Takeuchi, H., 1997, "Micellar-enhanced Ultrafiltration of Gold(III) with Nonionic Surfactant", J. Membrane Science, Vol. 133, pp. 189-194.

11. Maurice, C. F., et al. 1995, Mineral Processing, In: Flotation Science and Engineering, Part 2, pp.89-259, (Matis, K. A., Eds.), N.Y., Dekker.

12. Thomas, E., et al. 1992, Separations Based on Foams, In: Surfactant-Based Separation Processes, Part IV, pp. 233-320, (Scamehorn, J. F., et al. Eds.), N.Y., Dekker.

13. Malcolm D. E., Leahy G J., Neville T M. and Stuart KN. 1991, "Selective Ion Flotation of Gold from Alkaline Cyanide Solutions", AisIMM World Gold '91 Conference Cairns $21^{\text {th }}$ to $26^{\text {th }}$ April, pp. $121-131$.

14. Maruyama, H., Suzuki, A., Seki, H., 2000, "Adsorption of Water Soluble Proteins onto Bubbles in Continuous Foam Separation", J. Coll. Int. Sci., Vol. 224, pp. 76-83.

15. Bhattacharya, P., Ghosal, S. K., and Sen, K., 1991, "Effect of Physicochemical Parameters on the Separation of Proteins from Human Placental Extract by Using a Continuous Foam Fractionating Column”, Sep. Sci Technol., Vol. 26(10\&11), pp. 1279-1293.

16. Tharapiwattananon, N., Scamehorn, J.F., Osuwan, S., Harwell, J.H., and Haller, K.J., 1996, "Surfactant Recovery from Water Using Foam Separation", Sep. Sci. Technol., Vol. 31(9), pp. 1233-1258.

17. Koczo, K., and Racz, G., 1991, "Foaming Properties of Surfactant Solution", Colloids Surf., Vol. 56, pp. 59-82.

18. Uraizee F., and Ganesan, N., 1992, "Effect of Coalescence on the Performance of Continuous Foam Fractionation Column”. Sep. Sci. Technol., Vol. 27(7), pp. 937-953.

19. Konduru, R., 1992, "Adsorption studies of Aqueous Zinc Ions by Foam Fractionation in Simple Mode", J. Chem. Eng. Japan, Vol. 25, No. 5, pp. 555-560.

20. M. Hiraide, 1995, Foam Fractionation and Flotation, In: Encyclopedia of Analytical Science, pp. 1453, (Townshend, A., Eds.), F.L., Academic Press.

21. Akita, S., Rovira, M., Sastre, A.M., Hyodo, N., and Takeuchi, H., 1997, "Coacervation Characteristics of Nonionic Surfactants and Their Application to Metal Separation", Proceedings of International Symposium on Liquid-Liquid Two-phase Flow and Transport Phenomena, Antalya, Turkey, $3^{\text {th }}-7^{\text {th }}$ Nov. 1997, pp. 371-380. 